\title{
The CSIRO-QCCCE contribution to CMIP5 using the CSIRO Mk3.6 climate model
}

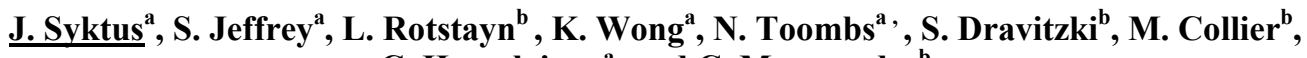 \\ C. Hamalainen ${ }^{a}$ and C. Moeseneder ${ }^{b}$ \\ ${ }^{a}$ Queensland Climate Change Centre of Excellence, Department of Environment and Resource Management, \\ 41 Boggo Road, Dutton Park QLD 4102, Australia \\ ${ }^{b}$ CSIRO Marine and Atmospheric Research, Private Bag 1, Aspendale VIC 3195, Australia \\ Email:.jozef.syktus@climatechange.qld.gov.au
}

\begin{abstract}
Fifth phase of the Climate Model Intercomparison Project (CMIP5) is the principal framework for coordinated climate modeling experimentation supporting the preparation of the IPCC $5^{\text {th }}$ Assessment Report to be released in 2013. About 20 modeling groups from around the world are undertaking the CMIP5 experiments and model data is being hosted on the Earth System Grid which consists of international data nodes and gateways (see http://cmip-pcmdi.llnl.gov/cmip5/).
\end{abstract}

The CMIP5 experimental design features a standard set of model simulations consisting of simulations based on historical concentration and emission changes, simulations along potential future pathways to 2100 , and a range of idealised experiments to understand climate sensitivity and to quantify key feedbacks. Projections of future climate are based on the new generation of emission scenarios, which were developed by the research community (Moss et. al., 2010). The CMIP5 experimental protocol provides four emission scenarios based on the Representative Concentration Pathways (RCPs), which are identified with their amounts of net radiative forcing input into the Earth's climate system at the end of the $21^{\text {st }}$ Century. They include following scenarios:

- A "no policy" RCP8.5 W/m²

- Two "stabilization" RCP6 W/m² and RCP4.5 W/m²;

- A “peak and decline” RCP2.6 W/m².

CSIRO Marine and Atmospheric Research and the Queensland Climate Change Centre of Excellence (QCCCE) are contributing to this international project using the CSIRO-Mk3.6 Atmosphere Ocean Global Climate Model (AOGCM). The Mk3.6 climate model is a substantial upgrade from its recent predecessors $\mathrm{Mk3.0}$ and Mk3.5, which were used to contribute to CMIP3. Upgrades included addition of an interactive aerosol scheme, which explicitly treats sulfate, dust, sea salt and carbonaceous aerosol. It also includes an updated radiation scheme and other changes to the atmospheric physics component. The CSIRO Mk3.6 climate model has been used to perform most of the long-term simulations which include the "core" experiments plus a number of "tier1" and "tier2" experiments specified by the CMIP5 experimental protocol (Taylor et al., 2011a).

This paper shows selected results from historical simulations for the period 1851 to 2005 using various combinations of radiative forcing (both natural and anthropogenic) and results from climate change projections for the period 2006 to 2100 . The analysis quantifies the relative contribution of various radiative forcing factors to the simulated changes in mean annual surface temperature during the 1981 to 2005 period. Results from the analysis show that simulations with natural forcing only resulted in small changes in the surface temperature, whereas the simulations with all forcing show statistically significant changes in the surface temperature over most of the Earth surface and these changes have magnitude comparable to observed changes. Furthermore, the rate of warming is greatest in the experiment with greenhouse gases only, where the cooling impact of anthropogenic aerosols is not accounted for. Model simulations show continuing warming and drying in subtropical land areas during the early part of $21^{\text {st }}$ century.

Keywords: Climate changes projections, CMIP5, CSIRO Mk3.6 model, Natural, Anthropogenic, Aerosols 


\section{INTRODUCTION}

The World Climate Research Programme's Working Group on Coupled Modelling (WGCM) held a historic meeting in Paris, France on 22-24 September 2008 where representatives from 20 of the global coupled climate modeling groups from around the world agreed to promote a new set of coordinated climate model experiments. These experiments are performed using experimental protocol defined by the fifth phase of the Coupled Model Intercomparison Project (CMIP5). Results from these experiments will provide the basis for the next Intergovernmental Panel on Climate Change Assessment (AR5), which is scheduled for publication in 2013. The CMIP5 experimental design has the following suites of experiments:

- Decadal hindcasts and prediction simulations;

- Long-term simulations (paleoclimate, historical and projections): and

- Atmosphere-only (prescribed SST) simulations for especially computationally-demanding models.

The "long-term" experiments features an extensive set of model simulations consisting of simulations based on historical concentration and emission changes; historical simulations evaluating various forcing factors such as natural and anthropogenic, simulations along potential future pathways until 2100 and beyond; and a range of idealised experiments to understand climate sensitivity and to quantify key feedbacks (Taylor et al., 2011). Projections of future climate are based on the new generation of emission scenarios, which were developed by the research community (Moss et. al., 2010). The CMIP5 experimental protocol provides four emission scenarios based on the Representative Concentration Pathways (RCPs), which are identified with their amounts of net radiative forcing input into the Earth's climate system at the end of the $21^{\text {st }}$ Century. They include following scenarios:

- A "no policy" RCP8.5 - radiative forcing of $8.5 \mathrm{~W} / \mathrm{m}^{2}$ and greenhouse gases concentration of 1370 ppm of $\mathrm{CO}_{2}$-equvalent in 2100;

- Stabilization RCP6 - radiative forcing of $6 \mathrm{~W} / \mathrm{m}^{2}$ and greenhouse gases concentration of $850 \mathrm{ppm}$ of $\mathrm{CO}_{2}$-equivalent in 2100;

- Stabilization RCP4.5 - radiative forcing of $4.5 \mathrm{~W} / \mathrm{m}^{2}$ and greenhouse gases concentration of 650 ppm of $\mathrm{CO}_{2}$-equivalent in 2100; and

- A "peak and decline" RCP2.6 - radiative forcing peaking at $3 \mathrm{~W} / \mathrm{m}^{2}$ before 2100 and then declining, and the greenhouse gases concentration peaking at $490 \mathrm{ppm} \mathrm{CO}_{2}$-equivalent before 2100 and then declining.

The CSIRO Mk3.6 climate model was used to complete most of the "long-term" simulations (see Collier et al., 2011 for details). In particular the CSIRO-QCCCE contribution to CMIP5 has produced relatively large ensemble size (typically 10 members) of historical and future simulations. In addition a range of historical experiments evaluating relative contribution of various forcing factors such as greenhouse gases, anthropogenic aerosols, natural (solar and volcanic), and ozone depletion was also completed.

\section{CSIRO MK3.6 CLIMATE MODEL AND CMIP5 FORCING DATASETS}

CSIRO Marine and Atmospheric Research and the Queensland Climate Change Centre of Excellence (QCCCE) are contributing to CMIP5 using the CSIRO Mark 3.6 (Mk3.6) climate model. The CSIRO Mk3.6 is the most recent version of the CSIRO Global Climate Model (GCM), which can be traced back to the twolayer model developed by Hal Gordon some 30 years ago (Gordon, 1981). It is a coupled atmosphere-ocean model with dynamical sea ice and soil canopy scheme with prescribed vegetation properties (see for other model details Gordon et al., 2010). The ocean, sea-ice and soil-canopy models are unchanged between Mk3.5 and Mk3.6. The atmospheric model is a spectral model (T63) that utilizes the flux form (Gordon, 1981) of the dynamical equations. The model has 18 vertical levels and a horizontal resolution of approximately $1.875^{\circ} \times 1.875^{\circ}$. The ocean model is based on version 2.2 of the Modular Ocean Model (Gordon et al., 2010). Every atmospheric grid-box is coupled to two oceanic grid-boxes. An enhanced north-south resolution in the ocean model was implemented with the aim of improving the representation of tropical variability. The ocean model thus has resolution of approximately $0.937^{\circ} \times 1.875^{\circ}$ and has 31 vertical levels. Several improved physical parameterizations were implemented in $\mathrm{Mk} 3.5$ to reduce biases and climate drift in the earlier Mk3.0 version (Gordon et al., 2002, Fig. 22). 
The main differences between Mk3.5 and Mk3.6 are the inclusion of an interactive aerosol scheme, which explicitly treats sulfate, dust, sea salt and carbonaceous aerosol. It also includes an updated radiation scheme and other changes to the atmospheric physics component. There are 11 prognostic mass tracers in the aerosol scheme: dimethyl sulfide (DMS), sulfur dioxide (SO2), sulfate, hydrophobic and hydrophilic forms of black carbon $(\mathrm{BC})$ and organic carbon, and four size bins of mineral dust, with radii ranging from $0.1-1,1-2,2-3$ and 3-6 $\mu \mathrm{m}$ respectively. The implementation of interactive aerosol scheme in the Mk3.6 allows for the investigation of the impact of aerosol on climate. For example, in a recent study Rotstayn et al. (2011) show that mineral dust has an important role in the simulation of Australian rainfall variability associated with ENSO.

The CMIP5 experimental design has provided a standard set of model forcing datasets such as solar forcing, land use, greenhouse gas emissions and concentrations, anthropogenic aerosols, along with tropospheric and stratospheric ozone (Taylor et al., 2011, see http://cmip-pcmdi.llnl.gov/cmip5/ for further information about CMIP5 forcing data). These forcing datasets were adopted for use with the CSIRO Mk3.6 model (Rotstayn et al., in preparation). Anthropogenic forcing agents in our runs are long-lived greenhouse gases (GHGs), ozone and aerosols. Changes in land cover and use are not included. Prescribed anthropogenic and biomass burning sources of sulfur, black carbon and organic aerosols are based on the recommended data sets for CMIP5 (Lamarque et al., 2010). Ozone concentrations are based on the AC\&C/SPARC ozone database (Cionni et al., 2011). The pre-

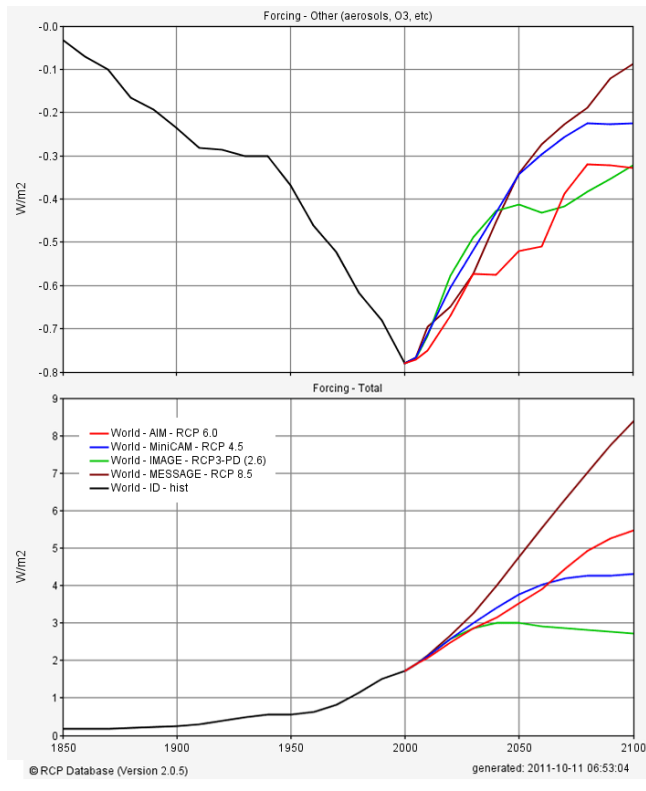

Figure 1: Global average aerosol forcing (upper) and the total net radiative forcing (lower) during the 1850 to 2100 period (units $\mathrm{W} / \mathrm{m}^{2}$ ). Source IASA RCP Database.

industrial, historical and future (RCP) concentrations of greenhouse gases (GHG) are available as global mean time series from the IIASA web site (http://www.iiasa.ac.at/webapps/tnt/RcpDb/dsd?Action=htmlpage\&page=welcome) and were adopted for use with the Mk3.6 model. The historical time series of annual-mean total solar irradiance recommended for CMIP5 includes estimates of both the 11-year solar cycle and changes in background irradiance (Lean, 2000). CMIP5 did not provide a dataset for volcanic forcing. A zonally averaged distributions of stratospheric sulfate representing volcanic forcing based on Sato et al. (1993) was used (http://data.giss.nasa.gov/modelforce/strataer/). The net total global average (top of atmosphere) radiative forcing and the net global average aerosol forcing are shown at Figure 1. Aerosols had negative forcing that peak at around 2005 and decline afterwards, whereas the total radiative forcing has been increasing steadily throughout the 1850 to 2100 period with marked increase in since the mid-70s.

Using the CMIP5 experimental protocol and recommended forcing datasets the CSIRO Mk3.6 climate model was used to complete a 1000 years long preindustrial control run, a substantial set of 10-member historical ensembles (for the 1850 to 2005 period), designed to evaluate the effects of changes in GHGs, aerosols, ozone and natural (solar and volcanic) forcing, and future projections using four RCPs. Here we show selected results from: (a) preindustrial control simulation; (b) historical run with "all forcings" which consist of GHGs, ozone, anthropogenic aerosols, and natural forcing; (c) historical run forced only by changes in GHGs; (d) historical run forced only by solar and volcanic (natural) forcing);

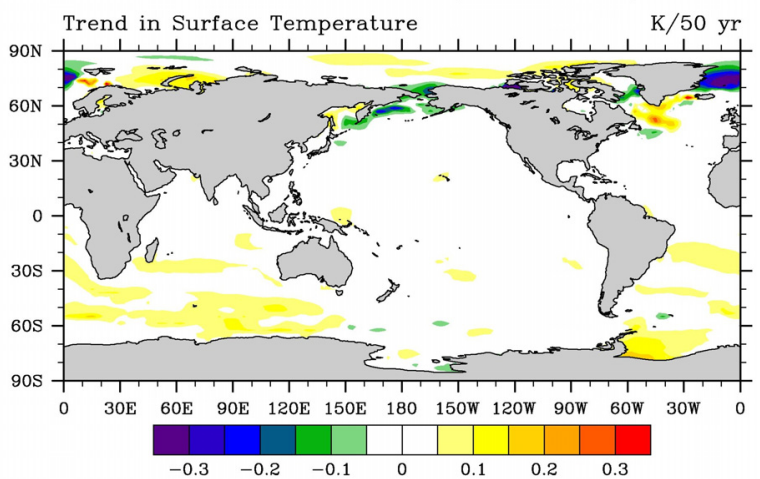

Figure 2: Global drift in sea surface temperature from pre-Industrial control run with CSIRO Mk3.6 climate model. Trend derived from 300 years of model integration (units: Kelvin/50years). 
and (e) projections for 2006 to 2100 using RCPs. Each historical run was initialized from states taken from years 80 to 200 of the 1000 year of the preindustrial control run, at intervals of 10 to 17 years. Each RCP run was initialized from the end of a run from the historical "all forcings" ensemble.

\section{RESULTS}

This section describes selected results from simulations completed with CSIRO Mk3.6 model contributing to the CMIP5 data archive. Figure 2 shows the drift in the sea surface temperature from the preindustrial control run. Trends computed from first 300 years of model integration shows that the model has small drift over the most of ocean surface with the exception of high latitudes especially in Greenland Sea area where the drift is larger. The global ocean temperature drift in the $\mathrm{Mk} 3.6$ is $0.02^{\circ} \mathrm{C} /$ century. When interpreting simulated temperature change during the $20^{\text {th }}$ century it is important to account for model drift which can potentially have a substantial impact on the simulated changes (Irving et al., 2011) and needs to be accounted for.

\subsection{Simulated surface temperature changes during late $20^{\text {th }}$ century}

This section shows simulated changes in the surface temperature from historical simulations. A comparison is made between the annual average temperature change during the 1981 to 2005 and the 1871 to 1970 periods for simulations with "all forcings", greenhouse gases only and natural forcing only using data from five-member ensembles. This approach is used to contrast the model response between simulations with natural forcing characterized by little net change in radiative forcing throughout the length of simulation, with simulations with anthropogenic forcing which show a sharp increase in concentration of greenhouse gases in the second half of $20^{\text {th }}$ century (see Figure 1) and a significant increase in emissions of anthropogenic aerosols. As expected surface temperature changes in the simulation with natural forcing show little change (Figure 3 bottom); the global average difference between the two periods was $0.01^{\circ} \mathrm{C}$, whereas simulations with all forcing show a substantial warming of $0.27^{\circ} \mathrm{C}$ (Figure 3 top). Temperature changes are tested for statistical significance using non-parametric bootstrap methods. Changes that are at the $95 \%$ or higher significance level are shown. Warming rate was highest in high latitudes and over land in the simulation with all forcing. This model simulated warming was smaller than the observed change which is $0.45^{\circ} \mathrm{C}$ (Brohan et al., 2006) and can be attributed to model mean annual surface temperature being warmer than observed during the 1900 to 1960 period (see Figure 4). However the model simulated rate of warming calculated as a temperature difference between 2001-2005 and $1850-1899$ is $\sim 0.71^{\circ} \mathrm{C}$ and compares closely with the observed rate of warming of $\sim 0.76^{\circ} \mathrm{C}$ (Brohan et al., 2006). Furthermore the rate of warming in model simulations with all forcing for the 1981 to 2005 period was very similar to observed changes and is $\sim 0.46^{\circ} \mathrm{C}$ (Figure 4 ).

Simulations with greenhouse gases only show the largest amount of warming, with global temperature increase of $0.79^{\circ} \mathrm{C}$ (Figure 3 middle)
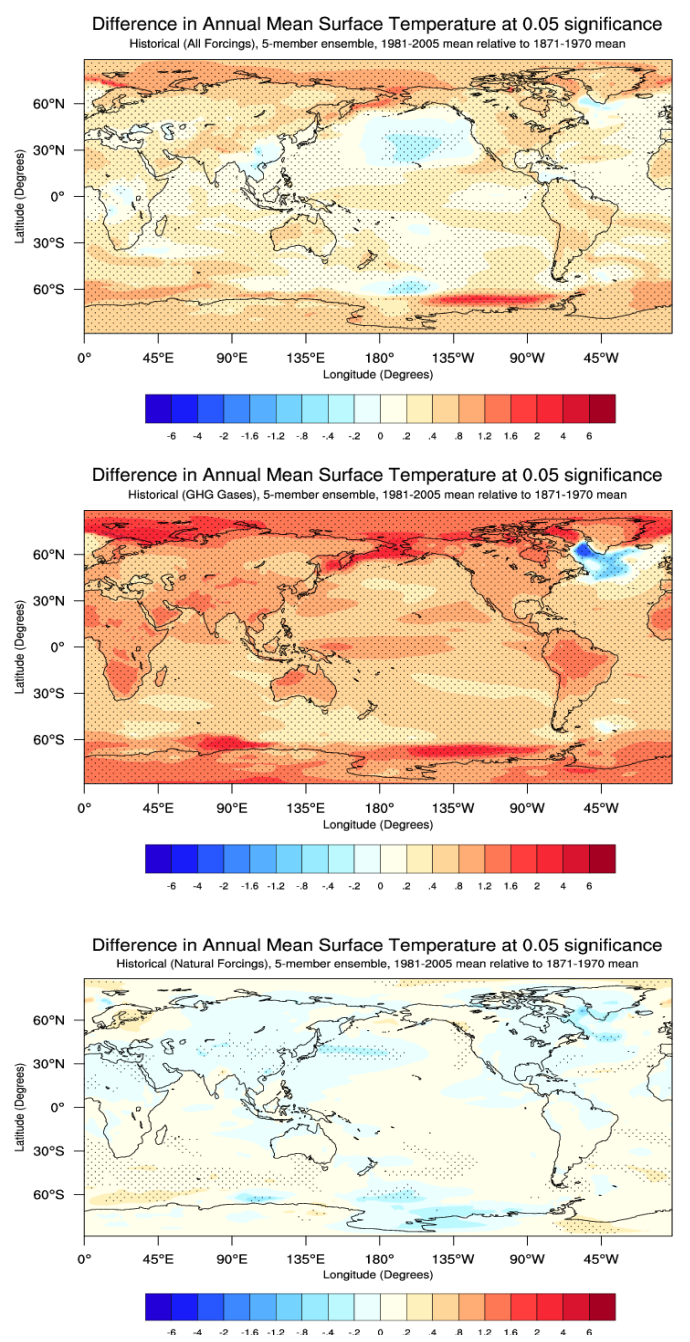

Figure 3: Mean annual surface temperature change between 1981 to 2005 period and 1871 to 1970 period from simulations with all forcing (top) GHGs (middle) natural forcing only (bottom). Statistically significant changes are stippled. 
during the 1981 to 2005 period. The major difference in the rate of warming between all forcings and GHGs only simulations results from the cooling effect of anthropogenic aerosols (see Figure 1). The net top of atmosphere anthropogenic aerosol (direct plus indirect) forcing from 1850 to 2000 in the CSIRO Mk3.6 model was estimated to be $-1.4 \mathrm{~W} / \mathrm{m}^{2}$ (Rotstayn et al., in preparation). This is a little larger in magnitude than the best estimate from observations of $-1.2 \mathrm{~W} / \mathrm{m}^{2}$ (Forster et al., 2007), and a little lower that the $-1.6 \pm 0.3 \mathrm{~W} /$ $\mathrm{m}^{2}$ estimate of Hansen et al (2011), though it is within the large uncertainty range.

\subsection{Simulated temperature change during early 21 st century}

Using RCPs and the Mk3.6 climate model simulates substantial warming during the $21^{\text {st }}$ century, especially for the RCP8.5 (Fig 4). Climate change projection data using the four RCPs has been used to compute projected changes in mean annual surface temperature during the 2006 to 2030 period (Figure 5). Model projections show warming of between $0.5^{\circ} \mathrm{C}$ and $0.67^{\circ} \mathrm{C}$ depending on the RCP used for this period as compared to 1981 to 2005 period. Figure 5 shows the pattern of warming for RCP2.6. There was a substantial amount of warming during this period with largest increase in surface temperature over sea ice areas in the ocean and over land areas. The patterns of warming are very similar for other RCPs simulations (not shown). Model simulations show a significant area in the North Atlantic with surface cooling which is associated with change in fresh water flux into the ocean from the melting Greenland ice sheet (Cai et al., 1997). The pattern of warming shown at Figure 5 resembles more of the pattern of warming in simulation with GHGs only (see Figure 3 middle) and can be explained by the relative decline in emissions of anthropogenic aerosols projected during the $21^{\text {st }}$ century in RCPs (see Fig 1). The projected decline in emissions of

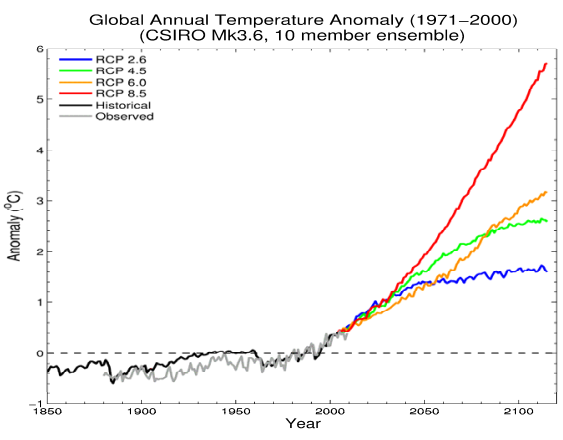

Figure 4: Global average annual surface temperature change (from baseline 1971-2000 period) during the 1850 to 2005 period for the historical (all forcing) and four RCP simulations for 2006 to 2100 period. Observational changes are also shown. the anthropogenic aerosols resulted in accelerated warming. This warming is a consequence of the combined effect of increasing concentration of GHGs and decreasing cooling impact of anthropogenic aerosols during the $21^{\text {st }}$ century.

\subsection{Historical and projected changes in hydrological cycle}

Analysis of model simulated precipitation during the late $20^{\text {th }}$ century and early $21^{\text {st }}$ century show a substantial changes in the pattern of precipitation distribution (Syktus et al., 2011). Model simulations show increased precipitation in the tropics, drying over subtropical lands and increased precipitation in high latitudes. We use the Standardized Precipitation Index (SPI; McKee et al., 1993) to illustrate the cumulative impact of precipitation changes on meteorological drought during the historical 1981 to

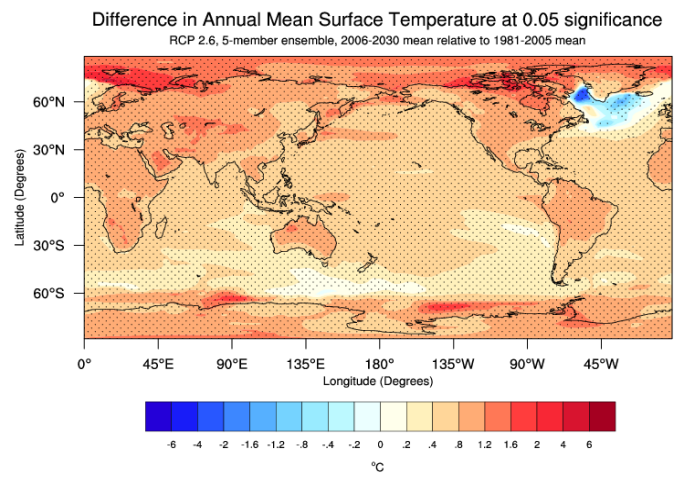

Figure 5: Projected changes (from 1981 to 2005 period) in mean annual surface temperature for period 2006 to 2030 from simulation with RCP2.6.

2005 period and the future (projected) 2006 to 2030

period. The SPI is a probability based index that considers the distribution of monthly precipitation. It is based on the probability of recording a given amount of precipitation, and the probabilities are standardized so that an index of zero indicates the median precipitation amount. The index is negative for drought, and positive for wet conditions. As the dry or wet conditions become more severe, the index becomes more negative or positive. Figure 6 shows results for SPI index accumulated over 12 months for extremely dry category (SPI < -2) averaged over the 1981 to 2005 period from historical simulations with all forcing and projected changes using RCP2.6 over the 2006 to 2030 period. Results show substantial increase in the occurrence of extremely dry conditions during the 1981 to 2005 period over land. In particular large changes are simulated in south-east China, Middle East, Amazon basin, central and southern Africa and north-west Canada. In Australia the model predicted an increased drying in south-west Western Australia and south- 
eastern Australia. These changes are consistent with observed changes in precipitation and drought patterns in Australia during the past decades. Model projected changes in drought during the 2006 to 2030 period show a general tendency towards increased drought conditions in sub-tropics and decreased drought in midto high latitudes. In particular the model simulates increased drought conditions in the south-west USA, the Mediterranean region in Europe, Africa, Middle East, south-east Asia, India, and in Chile and eastern Brazil. In Australia simulations show continuing drying in south-west Western Australia and Victoria, parts of South Australia and south-east Queensland. Projected changes in SPI are largest over NW Australia (a region of current increased precipitation) and may be consequence of projected decreases in emissions of anthropogenic aerosols in Asia (see Rotstayn et al., 2007 for details).

\section{CONCLUSIONS}

Analysis of data from simulations with CSIRO Mk3.6 climate model contributing to the CMIP5 project is presented in this paper. Selected results are presented highlighting the impact of anthropogenic forcing on the warming patterns during the late $20^{\text {th }}$ century and early part of $21^{\text {st }}$ century. In particular the cooling impact of

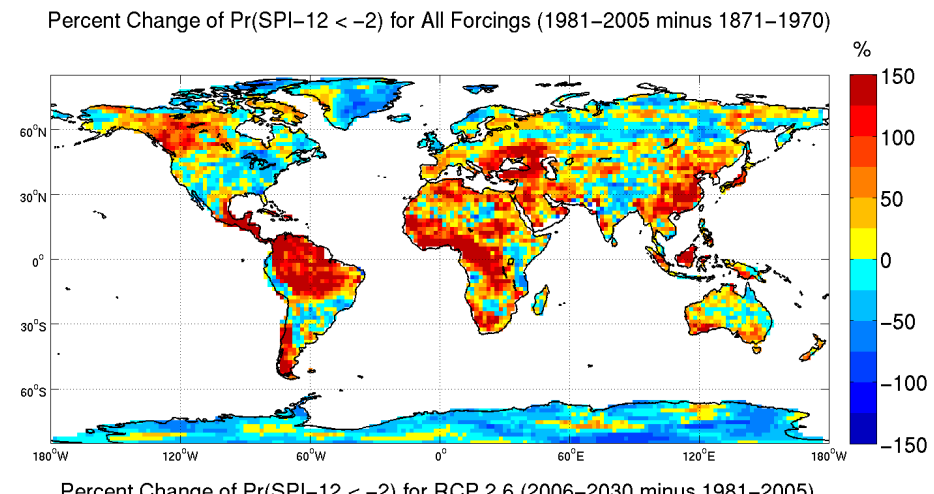

Percent Change of $\operatorname{Pr}(\mathrm{SPI}-12<-2)$ for RCP 2.6 (2006-2030 minus 1981-2005)

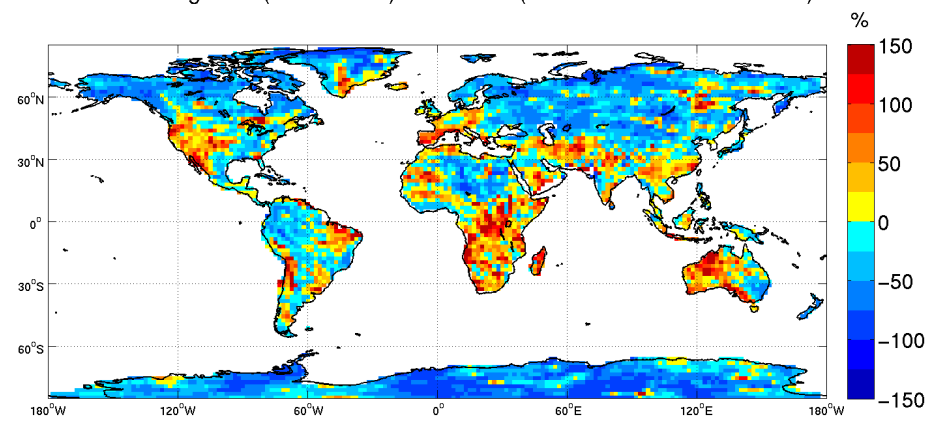

Figure 6: Simulated changes in the meteorological drought based on the SPI index from historical and projected simulations with the Mk3.6 model. Extremely dry conditions (SPI $<-2$ accumulated over 12 months intervals) for during the 1981 to 2005 and 2006 to 2030 periods are shown as a percent change from the base period (1871-1970 and 19812005 respectively).

anthropogenic aerosols resulted in much smaller rate of warming during the 1981 to 2005 period than it would be for the case where the anthropogenic greenhouse gases only were considered. Model simulations clearly demonstrate that the global surface temperature increase during the $20^{\text {th }}$ century is a direct result of anthropogenic GHGs emissions and were moderated by aerosols. Simulations with natural forcing showed very little change in surface temperature during the $20^{\text {th }}$ century. Model simulates continuous warming during the 2006 to 2030 period resulting from the combination of increasing concentration of greenhouse gases and decreasing emission of anthropogenic aerosols. Simulations show substantial changes in the hydrological cycle during the 1981 to 2030 period. In particular the model results show several regions with increased occurrence of drought during the late $20^{\text {th }}$ century and further drying in subtropical regions during the early $21^{\text {st }}$ century. These findings are consistent with results from the analysis of CMIP3 modeling results (Held and Soden, 2006).

\section{ACKNOWLEDGMENTS}

The Department of Environment and Resource Management's provided the computing resources used to perform the experiments and store the raw model output. The NCI NF provided the computing resources used to perform the post-processing of the raw model output, quality control and data publishing. The authors gratefully acknowledge the constructive comments from reviewers, which led to improvements of this paper.

\section{REFERENCES}

Brohan, P., Kennedy, J.J., Harris, I., Tett, S.F.B., and Jones, P.D. (2006). Uncertainty estimates in regional and global observed temperature changes: A new data set from 1850, Journal of Geophysical Research, $111, \mathrm{D} 12106$. 
Cai, W., Syktus, J., Gordon, H., and O'Farrell, S. (1997). Response of a Global Coupled Ocean-AtmosphereSea Ice Climate Model to an Imposed North Atlantic High Latitude Freshening. Journal of Climate, 10, pp.929-948.

Cionni, I., Eyring, V., Lamarque, J.F., Randel, W.J., Stevenson, D.S., Wu, F., Bodeker, G.E., Shepherd, T.G., Shindell, D.T., and Waugh, D.W. (2011). Ozone database in support of CMIP5 simulations: results and corresponding radiative forcing. Atmospheric Chemistry and Physics.

Collier, M.A., Jeffrey, S.J., Rotstayn, L.D., Wong, K.K., Dravitzki, S.M., Moseneder, C., Hamalainen, C., Syktus, J.I., Suppiah, R., Antony, J., El Zein, A., Artif, M. (2011, in press). The CSIRO-Mk3.6.0 Atmosphere-Ocean GCM: participation in CMIP5 and data publication. International Congress on Modelling and Simulation - MODSIM 2011.

Forster, P., Ramaswamy, V., Artaxo, P., Berntsen, T., Betts, R., Fahey, D.W., Haywood, J., Lean, J., Lowe, D.C., Myhre, G., Nganga, J., Prinn, R., Raga, G., Schultz, M., Van Dorland, R., (2007). Changes in Atmospheric Constituents and in Radiative Forcing, In: Climate Change 2007: The Physical Science Basis, edited by Solomon et al., Cambridge University Press, Cambridge, UK.

Gordon, H.B. (1981) Flux formulation of the spectral atmospheric equations suitable for use in long-term climate modelling. Monthly Weather Review, 109, 56-64.

Gordon, H.B., Rotstayn, L.D., McGregor, J.L., Dix, M.R., Kowalczyk, E.A., O'Farrell, S.P., Waterman, L.J., Hirst, A.C., Wilson, S.G., Collier, M.A., Watterson, I.G. and Elliott, T.I. (2002). The CSIRO Mk3 Climate System Model, CSIRO Atmospheric Research technical paper, 60, 130pp.

Gordon, H.B., O'Farrell, S.P., Collier, M.A., Dix, M.R., Rotstayn, L.D., Kowalczyk, E.A., Hirst, A.C., and Watterson, I.G. (2010). The CSIRO Mk3.5 Climate Model, Technical Report No. 21, The Centre for Australian Weather and Climate Research, Aspendale, Vic., Australia, 62 pp.

Hansen, J., Sato, M., Kharecha, P., and von Schuckmann, K. (2011) Earth's energy imbalance and implications. Atmospheric Chemistry and Physics Discussion, 11, 27031-27105, 2011.

Held I., and Soden, B. J. (2006). Robust response of the hydrological cycle to global warming. Journal of Climate, 19, 5686-5699.

Irving D.B., Perkins S.E., Brown J.R., Sen Gupta, A., Moise, A.F., Murphy, B.F., Muir, L.C., Colman, R.A., Power, S.B., Delage, F.P., and Brown, J.N. (2011). Evaluating global climate models for the Pacific island region. Climate Research, 49, 169-187.

Lamarque, J.-F., Bond, T.C., Eyring, V., Granier, C., Heil, A., Klimont, Z., Lee, D., Liousse, C., Mieville, A., Owen, B., Schultz, M.G., Shindell, D., Smith, S.J., Stehfest, E., Van Aardenne, J., Cooper, O.R., Kainuma, M., Mahowald, N., McConnell, J.R., Naik, V., Riahi, K., and van Vuuren, D.P. (2010). Historical (1850-2000) gridded anthropogenic and biomass burning emissions of reactive gases and aerosols: Methodology and application. Atmospheric Chemistry and Physics, 10, 7017-7039.

McKee, T.B., Doesken, N.J., and Kleist, J. (1993). The relationship of drought frequency and duration of time scales. Eighth Conference on Applied Climatology, American Meteorological Society, Jan 17-23, 1993, Anaheim CA, 179-186.

Moss, R.H., Edmonds, J. A., Hibbard, K. A., Manning, M. R., Rose, S. K., van Vuuren, D. P., Carter, T. R., Emori, S., Kainuma, M., Kram, T., Meehl, G. A., Mitchell, J. F. B., Nakicenovic, N., Riahi, K., Smith, S. J., Stouffer, R. J., Thomson, A. M., Weyant, J. P., and Wilbanks T. J. (2010). The next generation of scenarios for climate change research and assessment, Nature, 463, 747-756.

Rotstayn, L.D., Collier, M.A., Mitchell, R.M., Qin, Y., S.K. Campbell and S. M. Dravitzki (2011). Simulated enhancement of ENSO-related rainfall variability due to Australian dust. Atmos. Chem. Phys., 11, 65756592, doi: 10.5194/acp-11-6575-2011

Rotstayn, L.D., Collier, M.A., Dix, M.R., Feng, Y., Gordon, H.B., O’Farrell, S.P., et al. (2010). Improved simulation of Australian climate and ENSO-related rainfall variability in a global climate model with an interactive aerosol treatment. International Journal of Climatology, 30, 1067-1088.

Rotstayn, L.D., Cai, W., Dix, M.R., Farquhar, G.D., Feng, Y., Ginoux, P., Herzog, M., Ito, A., Penner, J. E., Roderick, M.L., and Wang, M. (2007). Have Australian Rainfall and Cloudiness Increased Due to the Remote Effects of Asian Anthropogenic Aerosols?, Journal of Geophysical Research, 112, D09202.

Syktus, J., Wong, K.K., Rotstayn, L.D., Jeffrey, S., Zhang, H., Toombs, N.R. and M.A. Collier (2011). Australia's hotter and drier future: Climate change projections using CMIP5 experimental design and the CSIRO Mk3.6 climate model. Greenhouse 2011, Cairns, 4-18 April 2011.

Taylor, K.E., Stouffer, R.J., \& Meehl, G.A. (2011, in press) An overview of CMIP5 and the Experimental design. Bulletin of the American Meteorological Society.

Taylor, K.E., Stouffer, R.J., \& Meehl, G.A. (2011a) A summary of the CMIP5 experiment design. Technical report, World Climate Research Programme. 